\title{
Calcium/Calmodulin-Dependent Protein Kinase IV Mediates IFN- $\gamma$-Induced Immune Behaviors in Skeletal Muscle Cells
}

\author{
RuiCai Gu MaoChao Ding $^{\mathrm{a}}$ DanDan Shi ${ }^{\mathrm{a}}$ Tao Huang ${ }^{\mathrm{a}} \quad$ MengXia Guo $^{\mathrm{a}} \quad$ Lei Yu $^{\mathrm{a}}$ \\ JiJie Hu WenHua Huang ${ }^{\mathrm{a}}$ Hua Liao ${ }^{\mathrm{a}}$
}

${ }^{a}$ Guangdong Provincial Key Laboratory of Construction and Detection in Tissue Engineering, Department of Anatomy, Southern Medical University, bepartment of Orthopaedics and Traumatology, Nanfang Hospital, Southern Medical University, Guangzhou, China

\section{Key Words}

Cam kinase IV (CaMKIV) $\bullet \mathrm{C}_{2} \mathrm{C}_{12}$ cell $\bullet$ Gene knockdown $\bullet$ IFN- $\gamma$

\begin{abstract}
Background/Aims: Whether calcium/calmodulin-dependent protein kinase IV (CaMKIV) plays a role in regulating immunologic features of muscle cells in inflammatory environment, as it does for immune cells, remains mostly unknown. In this study, we investigated the influence of endogenous CaMKIV on the immunological characteristics of myoblasts and myotubes received IFN- $\gamma$ stimulation. Methods: $\mathrm{C}_{2} \mathrm{C}_{12}$ and murine myogenic precursor cells (MPCs) were cultured and differentiated in vitro, in the presence of pro-inflammatory IFN- $\gamma$. CaMKIV shRNA lentivirus transfection was performed to knockdown CaMKIV gene in $\mathrm{C}_{2} \mathrm{C}_{12}$ cells. pEGFP-N1-CaMKIV plasmid was delivered into knockout cells for recovering intracellular CaMKIV gene level. CREB1 antagonist KG-501 was used to block CREB signal. qPCR, immunoblot analysis, or immunofluorescence was used to detect mRNA and protein levels of CaMKIV, immuno-molecules, or pro-inflammatory cytokines and chemokines. Costimulatory molecules expression was assessed by FACS analysis. Results: IFN- $\gamma$ induces the expression or up-regulation of MHC-I/II and TLR3, and the up-regulation of CaMKIV level in muscle cells. In contrast, CaMKIV knockdown in myoblasts and myotubes leads to expression inhibition of the above immuno-molecules. As well, CaMKIV knockdown selectively inhibits pro-inflammatory cytokines/chemokines, and co-stimulatory molecules expression in IFN- $\gamma$ treated myoblasts and myotubes. Finally, CaMKIV knockdown abolishes IFN- $\gamma$ induced CREB pathway molecules accumulation in differentiated myotubes. Conclusions: CaMKIV can be induced to up-regulate in muscle cells under inflammatory condition, and positively mediates intrinsic immune behaviors of muscle cells triggered by IFN- $\gamma$.
\end{abstract}

R.-C. Gu, M.-C. Ding and D.-D. Shi contributed equally to this work. 


\section{Cellular Physiology Cell Physiol Biochem 2018;46:351-364 \\ \begin{tabular}{l|l} 
and Biochemistry Published online: March 27, 2018 & $\begin{array}{l}\text { DO } 2018 \text { The Author(s). Published by S. Karger AG, Basel } \\
\text { www.karger.com/cpb }\end{array}$
\end{tabular}}

Gu et al.: CaMKIV Impacts on Immune Behaviors of Muscle Cells

\section{Introduction}

The calcium/calmodulin-dependent protein kinase IV (CaMKIV) is a downstream protein of $\mathrm{Ca}^{2+}$ signaling cascades. To be active, CaMKIV requires binding of $\mathrm{Ca}^{2+} / \mathrm{CaM}$ [1]. The expression of CaMKIV has been demonstrated predominately in cells of immune systems [2-4]. It has reported that CaMKIV inhibition/silence leads to the suppression of IFN- $\gamma$ production in T cells and B cells [5], as well, of antibody production, and of expression of CD80 and CD86 on B cells $[3,5,6]$. In addition, the expression of CaMKIV is developmentally regulated in monocyte-derived dendritic cells (DCs). Knocking off CaMKIV makes DCs expressing MHC class II fail to accumulate [4]. These reports suggest CaMKIV is essential for lymphocyte activation, proliferation and functions.

Skeletal muscle cells do not express detectable levels of major histocompatibility complex (MHC) molecules in physiological conditions while they had been demonstrated previously to be capable of expressing both MHC-I and MHC-II upon chronic inflammation condition (such as polymyositis) [7-9]. In vitro, human myoblasts and myotubes express MHC molecules (HLA-DR), either constitutively or after treatment with IFN- $\gamma[10,11]$. Muscle cells can also be induced to express the toll-like receptors (TLRs), some B7-related co-stimulatory/regulatory molecules, and adhesion molecules (e.g., intercellular adhesion molecule 1) [12-14]. This suggests that, under pro-inflammatory environment, skeletal muscle cells are capable of expressing immunological molecules and actively participate in muscle immune/inflammatory reactions. Whether CaMKIV signal effects on the intrinsic immunological capacities of muscle cells, like it does for immune cells, remains mostly unknown.

Reports for CaMKIV expression and function in muscle tissue are conflict. Several studies previously implicate CaMKIV in the $\mathrm{Ca}^{2+}$-dependent regulation of muscle gene expression, specifically in the activation of mitochondrial biogenesis and oxidative enzyme expression [1, 15-17]. However, other studies show a lack of CaMKIV expression in skeletal muscle, and CaMKIV is indicated not required for the maintenance of slow-twitch muscle phenotype and endurance training-induced mitochondrial biogenesis in murine skeletal muscle [18]. In our previous work, the striking up-regulation of CaMKIV protein level was observed in regenerated myofibers in Cardiotoxin (CTX)-damaged the tibialis anterior (TA) muscle, while, CaMKIV knockdown reverses IFN- $\gamma$ induced up-regulation of MHC class-I/II and TLR3 in myocytes [19], indicating CaMKIV can be induced to express or up-regulate in muscle cells under pro-inflammatory stimuli, and it may have a role on regulating the immune behaviors of myocytes. In this study, we extend our investigations on immune characteristics and CaMKIV expression in $\mathrm{C}_{2} \mathrm{C}_{12}$ cells and in murine myogenic precursor cells (MPCs), and demonstrated that, IFN- $\gamma$ induces the expression or up-regulation of the immuno-related molecules, and of CaMKIV in muscle cells. In striking contrast, CaMKIV knockdown in $\mathrm{C}_{2} \mathrm{C}_{12}$ cells leads to the expression inhibition of MHC class I/II, some pro-inflammatory cytokines/ chemokines, and co-stimulatory molecules. Finally, we found CaMKIV knockdown abolishes IFN- $\gamma$ induced CREB pathway molecules accumulation in differentiated myotubes.

\section{Materials and Methods}

Cell culture, shRNA or plasmid transfection, and pro-inflammatory stimuli

According to previous description, murine myogenic precursor cells (MPCs) were obtained from hind limb muscle of neonatal B6 mice [20]. Isolated MPCs and the thawed $\mathrm{C}_{2} \mathrm{C}_{12}$ cells (ATCC, USA) were cultured in Dulbecco's modified Eagle's medium Nutrient Mixture F-12 (DMEM/F12, Hyclone) containing with $10 \%$ fetal bovine serum (FBS, Gibco), 100 units $/ \mathrm{ml}$ penicillin, and $100 \mu \mathrm{g} / \mathrm{ml}$ streptomycin sulfate in a $5 \% \mathrm{CO}_{2}$-humidified chamber (Heraeus, Germany) at $37^{\circ} \mathrm{C}$. For differentiation studies, $\mathrm{C}_{2} \mathrm{C}_{12}$ cells and MPCs were cultured in DMEM, added with $2 \%$ horse serum. For CaMKIV shRNA transfection, $\mathrm{C}_{2} \mathrm{C}_{12}$ cells were starved overnight when grown to approximately 70-80\% confluence. The shRNA-mediated knockdown of CaMKIV (shRNA-CaMKIV) was performed using shRNA lentiviral particles [CaMKIV shRNA (m), sc-29903-V, 
Santa Cruz Biotechnology, Inc.] which were designed to suppress the production of CaMKIV in mouse cells. $\mathrm{C}_{2} \mathrm{C}_{12}$ cells that were transfected with shRNA lentiviral particles with noneffective scrambled shRNA sequences control (shRNA-control) [shRNA lentiviral particles-A (sc-108080), Santa Cruz Biotechnology, Inc.] were used as the control. Infections were performed following the manufacture's instructions. For the establishment of stable clones, $3 \mu \mathrm{g} / \mathrm{ml}$ puromycin (Santa Cruz Biotechnology, Inc.) was added into culture medium for selection and maintenance of cell lines expressing a transfected $p a c$ gene. Fresh puromycincontaining medium was replaced every 3-4 days until resistant colonies can be identified. Cell clones with stable CaMKIV knockdown were further cultured with complete medium including $1 \mu \mathrm{g} / \mathrm{ml}$ puromycin, or were induced into differentiated myotubes in the DMEM/F12 media containing 2\% horse serum and $1 \mu \mathrm{g} /$ $\mathrm{ml}$ puromycin for $72 \mathrm{~h}$. For recovering intracellular CaMKIV production in CaMKIV knockdown cells, double stranded improved DNA (http://www.jcat.de/) specific to mouse CaMKIV was synthesized (Sangon Biotech Co., China) and was inserted into the vector of pEGFP-N1 (Clontech) via XhoI and EcoRI sites screened for efficient recover CaMKIV (pEGFP-N1-CaMKIV). pEGFP-N1-CaMKIV plasmid transfection was performed using Lipofectamine $2000^{\mathrm{TM}}$ (Invitrogen): CaMKIV knockdown $\mathrm{C}_{2} \mathrm{C}_{12}$ cells were cultured in 24 well plates, transfected with $8 \mu$ g pEGFP-N1-CaMKIV plasmid. To obtain cells stably re-expressing CaMKIV, the cells

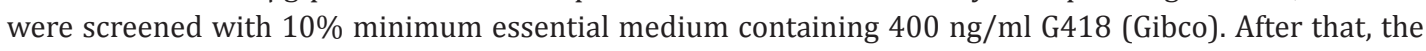
cells were fixed in $4 \%$ paraformaldehyde, incubated with DAPI to label the nuclei and examined under the fluorescence microscopy (fluorescence microscopy Olympus BX53, Japan). The CaMKIV recovered (reCaMKIV) cells were induced into differentiated myotubes in DMEM/F12 media containing 2\% horse serum for $72 \mathrm{~h}$. Effectiveness of the pEGFP-N1-CaMKIV plasmid transfection was verified by PCR and Western blots analysis. For blocking CREB activity in muscle cells, $250 \mu \mathrm{M}$ KG-501 (Sigma-Aldrich Co. LLC.) [21] were added into cell culturing system. For pro-inflammatory stimulation, myoblasts or myotubes transfected or not were treated with IFN- $\gamma(60 \mathrm{ng} / \mathrm{ml}, \mathrm{R} \& \mathrm{D}, \mathrm{USA})[22]$.

\section{RNA extraction and quantitative real-time PCR analysis}

Total RNA from MPCs or $\mathrm{C}_{2} \mathrm{C}_{12}$ cells was extracted using Trizol reagent (Invitrogen, USA), according to instructions provided by the manufacturer. 1 ug RNA was then used for reverse transcription (RT) with commercially available kit (Revert Aid First Strand cDNA Synthesis Kit, Fermentas; PrimeScript ${ }^{\mathrm{TM}}$ RT reagent Kit With gDNA Eraser, TaKaRa). Real-time polymerase chain reaction (PCR) was performed in triplicate with an ABI Step One Plus system (Applied Biosystems, USA) and a fluorescence-labeled SYBR Green/ROX qPCR Master Mix kit (Fermentas) using specific primers. CaMKIV, IL-1 $\beta$, TNF- $\alpha$, IL-6, MCP-1, MIP$1 \alpha$, CREB1, MEF-2a, MEF-2b, MEF-2d, Bcl-xl, STAT1, IRF1, JAK1 and with glyceraldehyde-3-phosphate dehydrogenase (GAPDH) taken as an endogenous control (primer sequences are listed in Table 1), were detected. To provide quantification, the point of product accumulation in the early logarithmic phase of the amplification plot was defined by assigning a fluorescence threshold above the background, defined as the threshold cycle $(\mathrm{Ct})$ number. Relative expression of different gene transcripts was calculated by the $\Delta \Delta \mathrm{Ct}$ method. The Ct of any gene of interest was normalized to the Ct of GAPDH. Fold changes (arbitrary units) were determined as $2^{-\Delta \Delta C t}$ [23].
Table 1 .Gene primer sequences. (All primers were designed from mouse sequences using the software Primer Premier 5)

\begin{tabular}{|c|c|}
\hline Genes & Primer sequence \\
\hline \multirow{2}{*}{ CaMKIV } & Forward: 5'CTGCCTGCTGTCATCGTC 3' \\
\hline & Reverse: 5' CAAATGTCTAAAGTTCCCT 3' \\
\hline \multirow{2}{*}{ IL-1 $\beta$} & Forward: 5'GCCCATCCTCTGTGACTC 3' \\
\hline & Reverse: 5'TGTGCCGTCTTTCATTAC 3' \\
\hline \multirow{2}{*}{ TNF- $\alpha$} & Forward: 5'GGCGGTGCCTATGTCTCA 3' \\
\hline & Reverse: 5'CCTCCACTTGGTGGTTTGT 3' \\
\hline \multirow{2}{*}{ IL-6 } & Forward: 5' GGCAATTCTGATTGTATG 3' \\
\hline & Reverse: 5’CTCTGGCTTTGTCTTTCT 3' \\
\hline \multirow{2}{*}{ MCP-1 } & Forward: 5'GGGTCCAGACATACATTAA 3' \\
\hline & Reverse: 5’ ACGGGTCAACTTCACATT 3' \\
\hline \multirow{2}{*}{ MIP-1 $\alpha$} & Forward: 5' CTGCCCTTGCTGTTCTTC 3' \\
\hline & Reverse: 5' CAAAGGCTGCTGGTTTCA 3' \\
\hline \multirow{2}{*}{ CREB1 } & Forward: 5'CCAAACTAGCAGTGGGCAGT 3' \\
\hline & Reverse: 5' CCCCATCCGTACCATTGTT 3' \\
\hline \multirow{2}{*}{ MEF-2a } & Forward: 5' GCTTTGTCGTACACTAACCCAGG 3' \\
\hline & Reverse: 5' GCATGCTCGAATCTGCTAATGT 3' \\
\hline \multirow{2}{*}{ MEF-2b } & Forward: 5' TGAAGAAGGCTTATGAGCTGAGC 3' \\
\hline & Reverse: 5' GCGCGCTGTTGAAGATGAT 3' \\
\hline \multirow{2}{*}{ MEF-2d } & Forward: 5' TCAACCACTCCAACAAGCTGTT 3' \\
\hline & Reverse: 5' GTACTCGGTGTACTTGAGCAGCA 3' \\
\hline \multirow{2}{*}{ Stat1 } & Forward: 5' CGCTGCCTATGATGTCTC 3' \\
\hline & Reverse: 5’ TTTCCGTAAGTTGTGCTG 3' \\
\hline \multirow{2}{*}{ Bcl-xl } & Forward: 5' CCTCCTCCCCGACCTATGAT 3' \\
\hline & Reverse: 5' CAAATCTATCTCCGGCGACCA 3' \\
\hline \multirow{2}{*}{ Irf1 } & Forward: 5’ AGCACGGCTGGGACATCA 3' \\
\hline & Reverse: 5' GTCTGGCAGGGAGTTCAT 3' \\
\hline \multirow{2}{*}{ Jak1 } & Forward: 5' CGGAACCAATGACAACGA3' \\
\hline & Reverse: 5’ TGAACTGGCATCAAGGAG3' \\
\hline \multirow{2}{*}{ GAPDH } & Forward: 5' TGCTCGCTGTATTCTTGGTG3' 3 \\
\hline & Reverse: 5' GGCTCCTTCTGTCGAGTGAC 3' \\
\hline
\end{tabular}




\section{Cellular Physiology Cell Physiol Biochem 2018;46:351-364

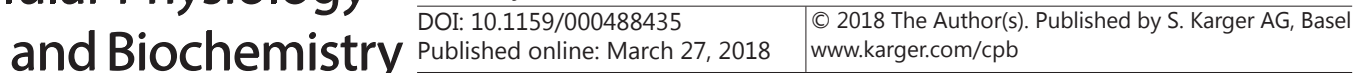

Gu et al.: CaMKIV Impacts on Immune Behaviors of Muscle Cells

Western blot analysis

Cell homogenates from MPCs, $\mathrm{C}_{2} \mathrm{C}_{12}$ cells, or mice brain tissue was prepared according to the manufacturer's protocol (KeyGEN, China). Protein concentrations were evaluated using a BCA assay kit (KeyGEN, China). Equal amounts of proteins were electrophoresed on 6-12\% SDS-polyacrylamide gel and transferred to Immobilon P membrane (Millipore, USA). Membranes were blocked in 5\% non-fat dried milk in Tris-buffered saline/Tween-20 (TBS-T: $20 \mathrm{mM}$ Tris, pH7.5, $150 \mathrm{mM} \mathrm{NaCl,} \mathrm{0.05 \%} \mathrm{Tween-20)} \mathrm{for} 1 \mathrm{~h}$ at RT. The following antibodies were used for detection: Mouse monoclonal anti-TLR3 (1:1000, NOVUS, USA); Rabbit polyclonal anti-CaMKIV (1:2000, Abcam, USA); Rabbit polyclonal anti-p-CaMKIV (phosphor T200) (1:2000, Abcam, USA); Rabbit polyclonal anti-MHC Class I (H-2K $, 1: 1000$, Abcam, USA); Mouse monoclonal anti-MHC-II (H2-Ea, 1:400, Santa Cruz, USA); Mouse monoclonal anti-CREB1 (1:1000, ImmunoWay, USA); Rabbit polyclonal anti-p-CREB1 (phospho Ser133) (1:1000, ImmunoWay, USA); Mouse monoclonal antiGAPDH (1:4000, KANGCHEN, China). Primary antibodies were incubated for $12 \mathrm{~h}$ at $4{ }^{\circ} \mathrm{C}$ in $5 \%$ non-fat dried milk in TBS-T. The membrane was then washed three times in TBS-T and incubated for $1 \mathrm{~h}$ at RT with horseradish peroxidase conjugated goat anti-rabbit IgG (1:5000, Fudebio, China) or goat anti-mouse IgG (1:2000, CST, USA), in 5\% non-fat dried milk in TBS-T. After washing three times in TBS-T, the protein bands were visualized by enhanced chemiluminescence (ECL) detection reagents (Applygen Technologic Inc., China). Immunoreactive bands was detected by the ECL detection system (Protein Simple, USA), and densitometric values were analyzed with ImageJ v1.42 software (National Institutes of Health, USA). Relative expression of each immunoreactive band was calculated by comparison with GAPDH. For antiCaMKIV antibody neutralizing experiment, the CaMKIV antibody was preincubated with recombinant CaMKIV peptide (1:1000, Abcam, USA) before the further incubation.

\section{Flow cytometric analysis}

$\mathrm{C}_{2} \mathrm{C}_{12}$ myoblasts and myotubes received different treatments were digested by $0.25 \%$ trypsin with 0.04\% EDTA (Gibco, USA), and centrifuged at $1000 \mathrm{rpm}$ for $3 \mathrm{~min}$. After washing twice by ice-cold PBS, single cell suspensions $\left(1 \times 10^{6}\right.$ cells/sample in $100 \mu \mathrm{l}$ of PBS $)$ were stained with following antibodies for $30 \mathrm{~min}$ at $25-30^{\circ} \mathrm{C}$ separately: phycoerythrin (PE)-conjugated anti-mouse CD40, allophycocyanin (APC)conjugated anti-mouse PD-L1, fluorescein isothiocyanate (FITC)-conjugated anti-mouse CD86, or FITCconjugated anti-mouse ICAM-1 (all from Biolegend, USA). Cells were washed twice with $1 \mathrm{ml}$ PBS again and then resuspended in $200 \mu \mathrm{l}$ PBS before analyzed on a FACS AriaII flow cytofluorometer (BD Biosciences) using FlowJo7.6.1 software. Samples were gated on live cells and $10^{5}$ live cell events per sample were collected.

\section{Immunofluorescence detection}

For immunofluorescent labeling, cells were firstly plated on microscope cover glass (Nest, China), and then fixed in cold acetone for $10 \mathrm{~min}$, permeabilized with $0.1 \%$ Triton X-100 for $10 \mathrm{~min}$ before washed twice in PBS and incubated with Rabbit polyclonal MyoD (1:200, Santa Cruz); Rabbit polyclonal myogenin (1:200, Santa Cruz); Rabbit polyclonal anti-p-CaMKIV (phosphor T200, 1:200, Abcam, USA); Rabbit polyclonal antiCaMKIV (1:200, Abcam, USA); Mouse anti-mouse H-2K $\mathrm{K}^{\mathrm{b}}$ (1:200, BD Biosciences); Mouse monoclonal H2-Ea (1:200, Santa Cruz); Goat polyclonal TLR3 (1:200, Santa Cruz), respectively. FITC-conjugated donkey antigoat IgG (1:400, Santa Cruz), Texas Red-conjugated goat anti-rabbit IgG (1:400, Santa Cruz), Rhodamineconjugated rabbit anti-mouse IgG (1:400, Santa Cruz), or Alexa Fluor 488 goat anti-rabbit IgG (1:500, Beyotime, China) were used as secondary antibodies. Nuclei were counterstained with DAPI (Santa Cruz). Slides were then viewed under Olympus BX53 fluorescence microscope (Olympus, Japan).

Statistical Analysis

All data are expressed as mean \pm standard deviation (SD). One-way ANOVA was used for multiple comparisons (Duncan's multiple range test) using SPSS ver.13.0 software. $P$ values $<0.05$ were considered as statistically significant.

\section{Results}

IFN- $\gamma$ induces the expression or up-regulation of immuno-molecules and CaMKIV in myoblasts and myotubes from $C_{2} C_{12}$ and murine myogenic precursor cells

Under physiological conditions, MHC class I and II is virtually undetectable in muscle. However, MHC expression is strongly up-regulated on the muscle fiber in inflammatory 


\section{Cellular Physiology and Biochemistry

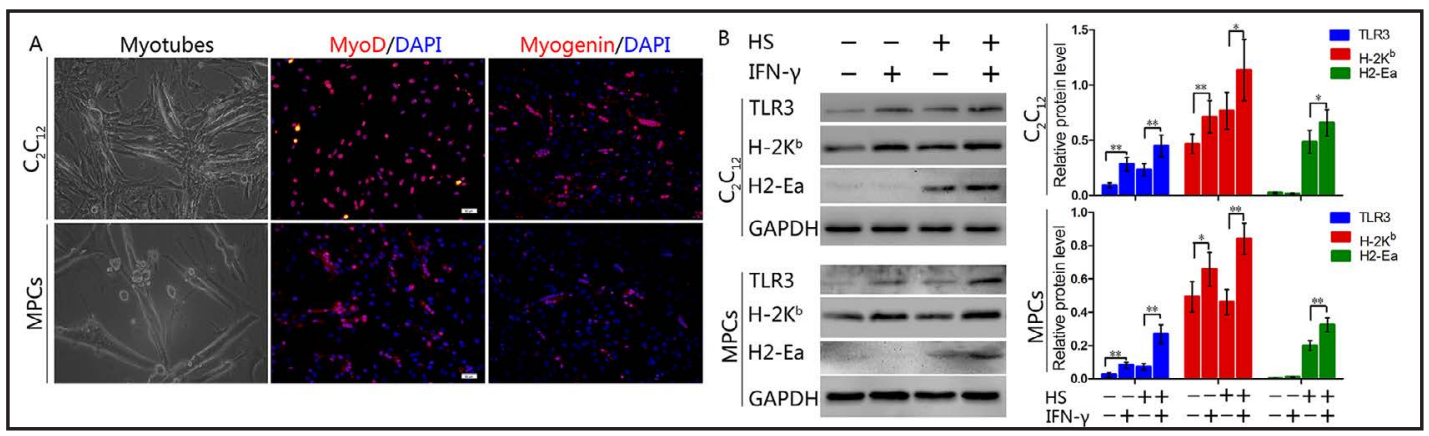

Fig. 1. IFN- $\gamma$ induces $\mathrm{H}-2 \mathrm{~K}^{\mathrm{b}}$, TLR3 and $\mathrm{H} 2$-Ea expression or up-regulation in myoblasts and myotubes. (A) $\mathrm{C}_{2} \mathrm{C}_{12}$ and murine myogenic precursor cells (MPCs) fused into multinucleated myotubes, and expressed MyoD and Myogenin after $72 \mathrm{~h}$ horse serum differentiation; (B) Western blots analysis showing protein level changes of $\mathrm{H}-2 \mathrm{~K}^{\mathrm{b}}$, TLR3 and $\mathrm{H} 2$-Ea in $\mathrm{C}_{2} \mathrm{C}_{12}$ cells and MPCs. The relative band intensities from western blots experiments were normalized to the level of GAPDH and analyzed. One-way ANOVA was used for multiple comparisons. All data are presented as mean \pm SD $(n=3) .\left({ }^{*} p<0.05\right.$ and $\left.{ }^{* *} p<0.01\right)$. Bar $=50 \mu \mathrm{m}$.

muscle diseases, such as polymyositis (PM) [7-9]. Muscle fibers are therefore believed to be the primary target of the immune attack in inflammatory myopathies. Since we already reported immuno-molecules expression in $\mathrm{C}_{2} \mathrm{C}_{12}$ myoblasts and myotubes, involving MHC-I molecule $\mathrm{H}-2 \mathrm{~K}^{\mathrm{b}}$, MHC-II molecule H2-Ea and TLR3 [19], here we further evaluated the above molecules expression in murine myogenic precursor cells (MPCs). $\mathrm{C}_{2} \mathrm{C}_{12}$ cells, or MPCs were cultured in IFN- $\gamma$-constructed inflammatory environment, added with or without $2 \%$ horse serum. In agreement with the analysis results of $\mathrm{C}_{2} \mathrm{C}_{12}$ cells, we observed MPCs survived well and can be successfully differentiated to form multinucleated myotubes under horse serum administration (Fig. 1A). In myoblasts, $\mathrm{H}-2 \mathrm{~K}^{\mathrm{b}}$ and TLR3 continuously low-expressed, and their protein levels significantly up-regulated by $72 \mathrm{~h}$-IFN- $\gamma$ treatment. Differentiated myotubes expressed $\mathrm{H}-2 \mathrm{~K}^{\mathrm{b}}$ and TLR3 more highly than myoblasts after inflammatory stimuli. H2-Ea was only detected in myotubes, and the level was significantly increased in the presence of IFN- $\gamma$ (Fig. 1B).

CaMKIV protein is reported to be undetectable in skeletal muscle in some previous studies, and thus CaMKIV is believed to be not required for functioning as endogenous mediators of activity-dependent changes in myofiber phenotype [18]. Recently we found regenerated new myofibers in CTX-damaged muscle highly expressed CaMKIV [19], hence, it is possible that CaMKIV expression is inducible in myocytes under inflammatory environment. To definitively establish this point, in this study, we investigated CaMKIV protein levels in $\mathrm{C}_{2} \mathrm{C}_{12}$ cells and MPCs by immunoblot analysis and evidenced the results by the extra CaMKIV antibody competition test. As expected, CaMKIV mRNA level was rather low in myoblasts and differentiated myotubes, but significantly up-regulated in muscle cells after $72 \mathrm{~h}$-IFN- $\gamma$ stimuli (Fig. 2A), which implies that, although absent under normal culture conditions, CaMKIV is inducible in the presence of IFN- $\gamma$. Consistent with the previous reports [18], our protein analysis demonstrated that, 3 bands closed with each other, can be recognized in myoblasts and myotubes. Among them, 2 bands were not affected by CaMKIV antibody competition, but very interestingly, the first band, which can be observed in IFN- $\gamma$ treated myoblasts and myotubes, disappeared after antibody competition, as that happened in brain tissue after antibody competition (Fig. 2B, C). Hence, we believe CaMKIV protein can be induced to express or up-regulate in muscle cells after pro-inflammatory stimuli, which is further evidenced by a marked increase of $\mathrm{p}$-CaMKIV protein level in IFN- $\gamma$ treated myoblasts and myotubes (Fig. 2B, C), and by an immunofluorescence staining results (Fig. 2D).

shRNA transfection inhibits CaMKIV expression in $C_{2} C_{12}$ cells under the IFN- $\gamma$ induced proinflammatory milieu

Using CaMKIV-shRNA lentivirus knockdown skill, we already obtained $\mathrm{C}_{2} \mathrm{C}_{12}$ cell clones with CaMKIV gene silence [19]. To definitively confirming knockout efficiency of CaMKIV 


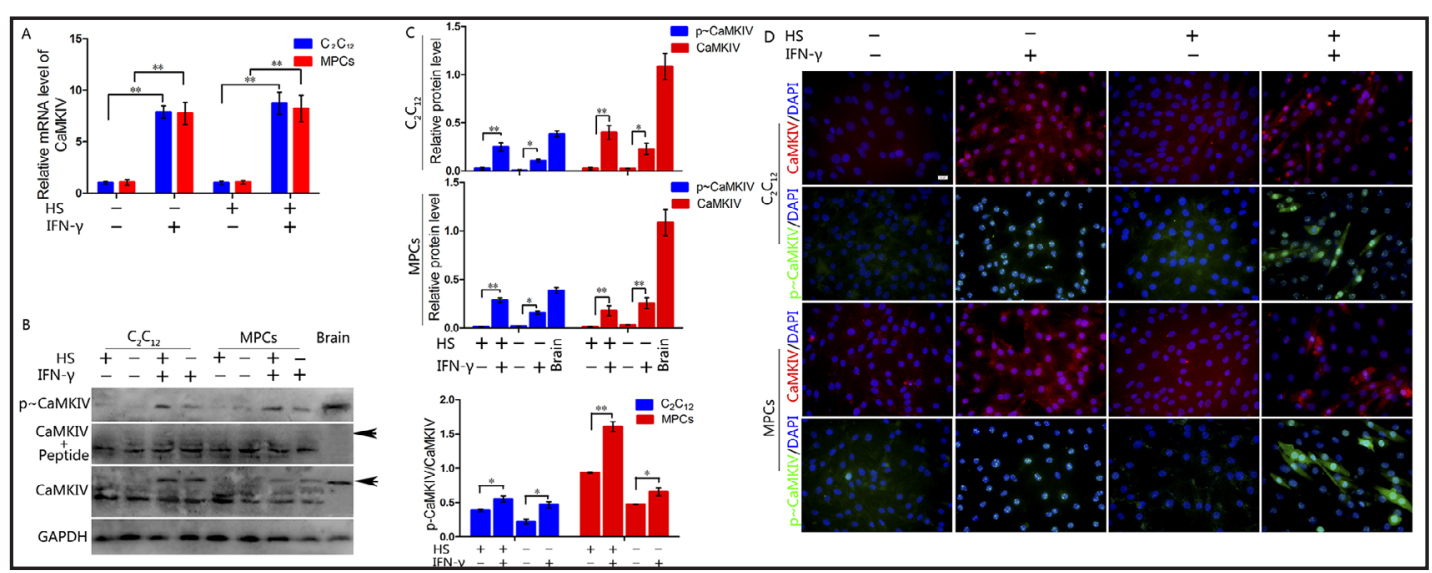

Fig. 2. IFN- $\gamma$ induces the up-regulation of CaMKIV in myoblasts and myotubes. (A) mRNA levels of CaMKIV in $\mathrm{C}_{2} \mathrm{C}_{12}$ cells and MPCs were quantified by qRT-PCR; (B) CaMKIV protein expression in $\mathrm{C}_{2} \mathrm{C}_{12}$ cells and MPCs was showed by Western blots analysis; $(\mathrm{C})$ The relative band intensities from western blots experiments were normalized to the level of GAPDH and analyzed. Ratio of p-CaMKIV vs CaMKIV measured by densitometric analysis of immunoblots. (D) Representative immunofluorecence staining results of CaMKIV and p-CaMKIV proteins in $\mathrm{C}_{2} \mathrm{C}_{12}$ cells and MPCs. Black arrow indicates CaMKIV band. One-way ANOVA was used for multiple comparisons. All data are presented as mean \pm SD $(n=3) .\left({ }^{*} p<0.05\right.$ and $\left.{ }^{* *} p<0.01\right)$. Bar $=20 \mu m$.

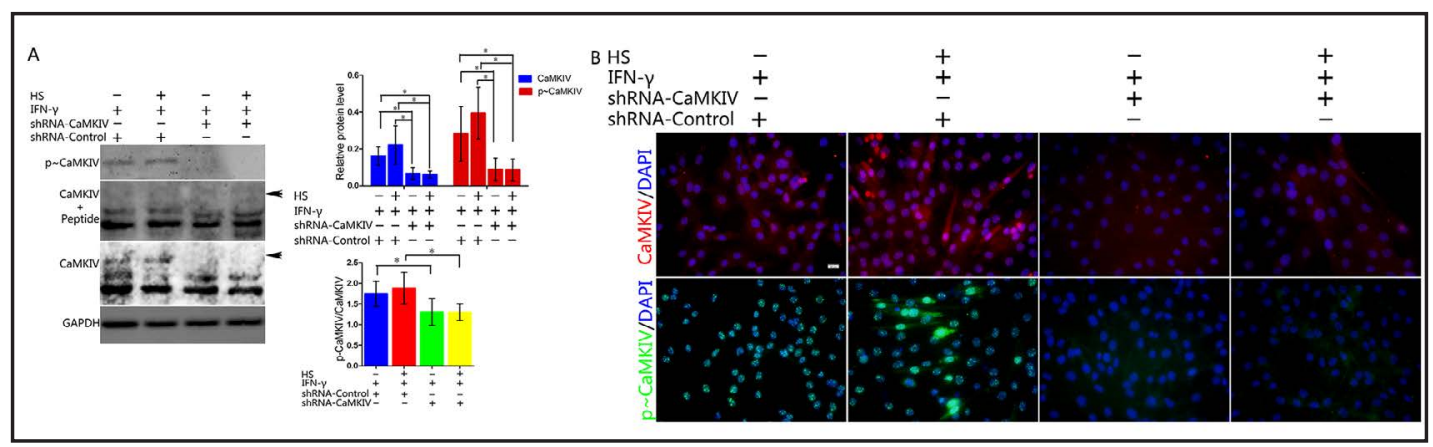

Fig. 3. Transfection of CaMKIV-shRNA lentivirus inhibits CaMKIV expression in $\mathrm{C}_{2} \mathrm{C}_{12}$ cells under the IFN- $\gamma$ induced inflammatory milieu. (A) CaMKIV protein expression in CaMKIV knockdown cells and in sc shRNA control cells were showed by Western blots analysis. The relative band intensities from western blots experiments were normalized to the level of GAPDH and analyzed. Ratio of p-CaMKIV vs CaMKIV measured by densitometric analysis of immunoblots. (B) Immunofluorecence staining results of CaMKIV and p-CaMKIV in CaMKIV knockdown cells and in sc shRNA control cells. Black arrow indicates CaMKIV band. One-way ANOVA was used for multiple comparisons. All data are presented as mean $\pm S D(n=9)$. (* $p<0.05$ and ** $\mathrm{p}<0.01$ ). Bar $=20 \mu \mathrm{m}$.

gene in muscle cells, we repeated CaMKIV knockdown experiment and checked up CaMKIV protein absence by the CaMKIV antibody competition supportive-immunoblot analysis. For that, $\mathrm{C}_{2} \mathrm{C}_{12}$ cells were cultured, starved overnight, and transfected with CaMKIV-shRNA lentiviral particles. shRNA lentiviral particles with noneffective scrambled shRNA sequences were used as the control. Consistent with our previous report [19], we found cell clones with stable CaMKIV knockdown survived and proliferated well in puromycin-added medium, and can be successfully induced to form multinucleated myotubes expressed MyoD and Myogenin, under horse serum administration for $72 \mathrm{~h}$. Since CaMKIV is undetectable in normal cultured $\mathrm{C}_{2} \mathrm{C}_{12}$ cells, we cultured or differentiated transfected cell clones in presence of IFN- $\gamma$ about $72 \mathrm{~h}$ before the analysis. Western blot were carried out to monitor CaMKIV gene knockdown in transfected cells. Not surprisingly, under IFN- $\gamma$ stimulation, sc shRNA treated control myoblasts and myotubes expressed CaMKIV protein, which is not affected by CaMKIV antibody competition. However, CaMKIV levels were significantly down-regulated 
in shRNA-CaMKIV transfected myoblasts and myotubes (Fig. 3A). In addition, CaMKIV protein absence in the transfected cells was further confirmed by our immunofluorescence detection results (Fig. 3B).

CaMKIV inhibition reverses IFN- $\gamma$ induced up-regulation of pro-inflammatory cytokines/ chemokines in $C_{2} C_{12}$ myoblasts and myotubes

Human myoblasts and differentiated myotubes have been demonstrated to up-regulate HLA-I (MHC-I) and TLR3, or express HLA-II antigen HLA-DR under the treatment with IFN- $\gamma$ in vitro $[10,12]$. Our recent immunobloting analysis supported this point, and we further found endogenous CaMKIV signal interferes with immunological capacities of muscle cells [19]. Here, we re-validated the effects of CaMKIV on immune-molecules expression in muscle cells received CaMKIV-shRNA or the control sc shRNA treatment, through immunofluorescence staining. Consistently, we observed that, under IFN- $\gamma$-constructed proinflammatory condition, CaMKIV knockdown reversed IFN- $\gamma$ induced up-regulation of $\mathrm{H}-2 \mathrm{~K}^{\mathrm{b}}$ and TLR3 in myoblasts and myotubes, and of H2-Ea in myotubes (Fig. 4A).

The secretion of soluble mediators, such as IL-1, IL-6, IL-15, MCP-1, TGF- $\beta$, and TNF- $\alpha$ has been described in muscle cells of inflammatory myopathies $[24,25]$, or in cultured myoblasts received IFN- $\gamma$, IL-1 $\alpha$, IL-1 $\beta$, TNF- $\alpha$ or LPS stimulation [26]. Using qRT-PCR analysis, we demonstrated that, sc shRNA transfected $\mathrm{C}_{2} \mathrm{C}_{12}$ myoblasts and myotubes constitutively expressed low levels of IL-1 $\beta$, IL-6, TNF- $\alpha$, MIP- $1 \alpha$ and MCP-1. After IFN- $\gamma$ stimulation, myoblasts and myotubes up-regulated IL- $1 \beta$, IL- 6 and MIP- $1 \alpha$ expression. However, TNF- $\alpha$ and MCP-1 were observed to increased gene levels only in horse serum-differentiated

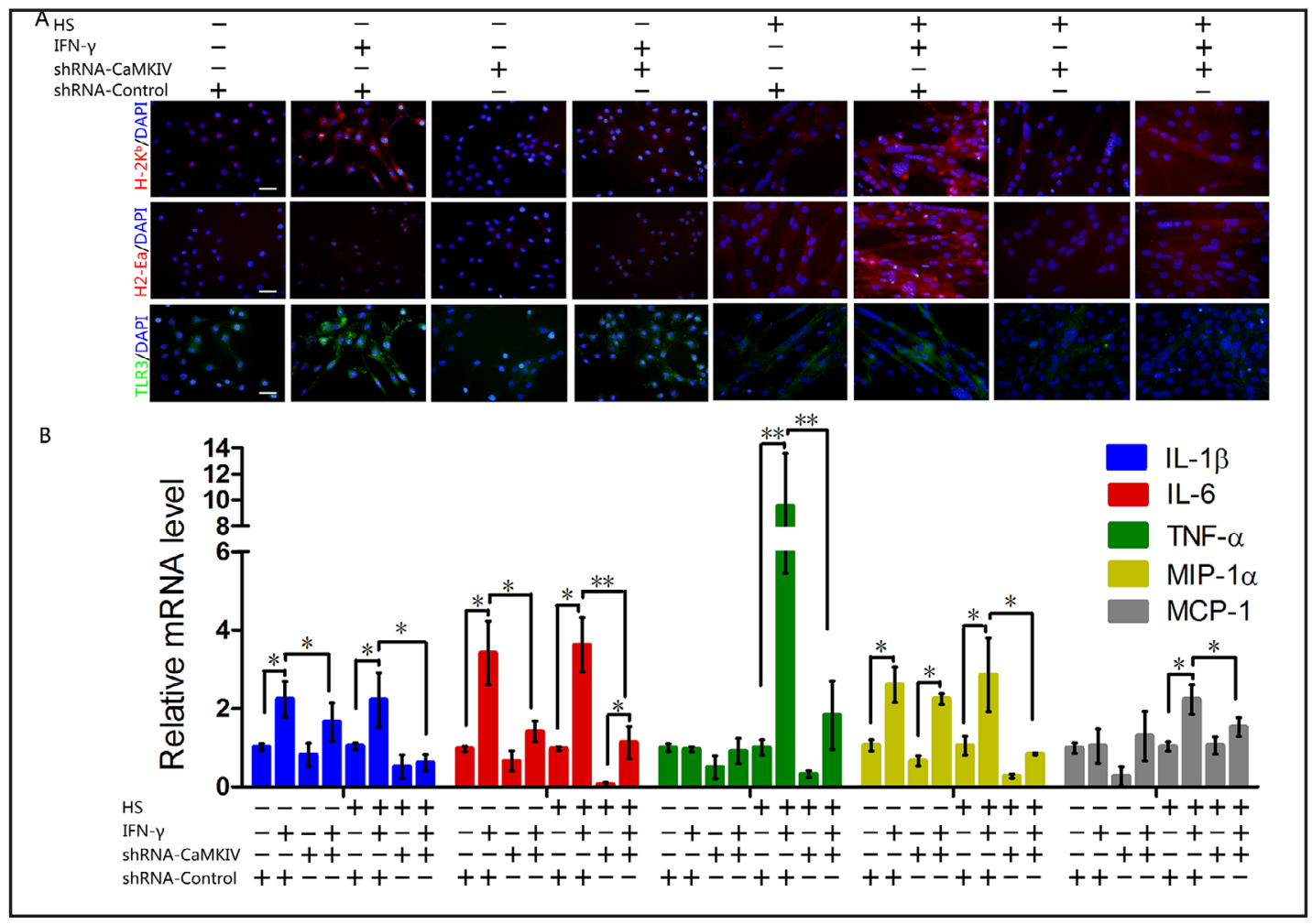

Fig. 4. CaMKIV knockdown reverses IFN- $\gamma$ induced up-regulation of MHC-I/II and TLR3, and the production of pro-inflammatory cytokines/chemokines in $\mathrm{C}_{2} \mathrm{C}_{12}$ cells. (A) Immunofluorecence staining results of $\mathrm{H}-2 \mathrm{~K}^{\mathrm{b}}$, H2-Ea and TLR3 in CaMKIV knockdown cells and in sc shRNA control cells; (B) mRNA levels of IL-1 $\beta$, IL-6, TNF- $\alpha$, MIP- $1 \alpha$ and MCP-1 in CaMKIV knockdown cells and in sc shRNA control cells were quantified by qRT-PCR. One-way ANOVA was used for multiple comparisons. All data are presented as mean \pm SD $(n=9)$. (* $\mathrm{p}<0.05$ and $\left.{ }^{* *} \mathrm{p}<0.01\right)$. Bar $=20 \mu \mathrm{m}$.

\section{KARGER}


myotubes, but not in myoblasts (Fig. 4B). Of note, CaMKIV knockdown decreased IL-6 level in IFN- $\gamma$ treated myoblasts. Interestingly, in CaMKIV gene deficient myotubes received IFN- $\gamma$ administration, mRNA levels of IL-1 $\beta$, IL-6, TNF- $\alpha$, MIP- $1 \alpha$ and MCP-1 markedly downregulated, comparing to the sc shRNA treated control cells (Fig. 4B), suggesting CaMKIV signal selectively suppresses the production of cytokines and chemokines in IFN- $\gamma$ treated muscle cells, and this inhibition mainly occurred in differentiated myotubes.

CaMKIV knockdown selectively inhibits co-stimulatory molecules expression in IFN- $\gamma$ treated myoblasts and myotubes

Co-stimulation signals are crucial to the activation of lymphocytes and development of immune response. Muscle cells have been considered as the facultative antigen-presenting cells (APCs) that maintain a muscle-directed immune response, and some co-stimulatory molecules, including CD40, inducible costimulator-ligand (ICOS-L), programmed deathligand 1 (PD-L1) and intercellular adhesion molecule (ICAM-1), had been identified in muscle fibres of myositis $[10,27,28]$, and were inducible in human myoblasts in vitro [14].

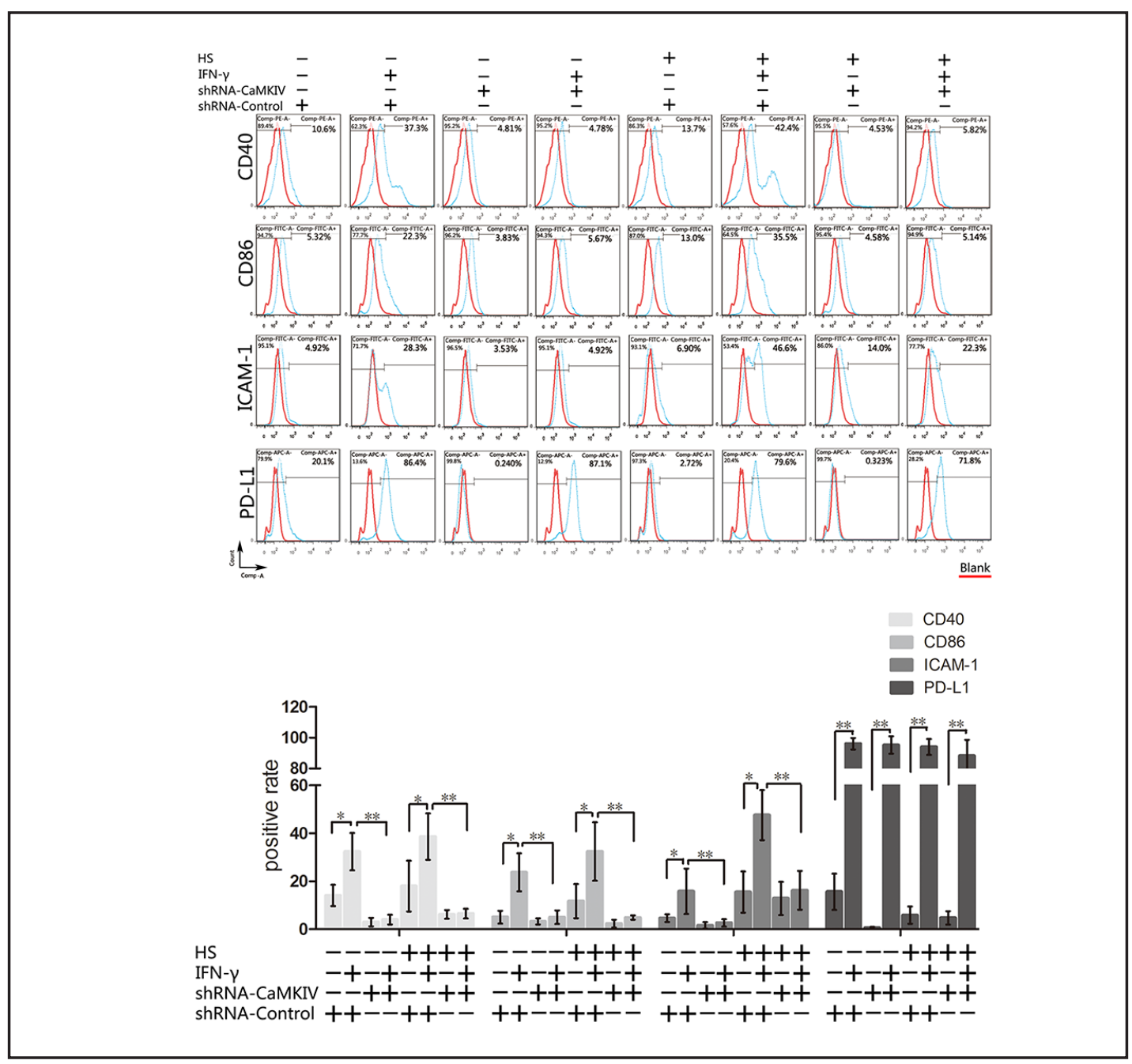

Fig. 5. CaMKIV knockdown inhibits IFN- $\gamma$ induced co-stimulatory molecules expression in $\mathrm{C}_{2} \mathrm{C}_{12}$ myoblasts and myotubes. Flow cytometric analysis of the percentages of CD40, CD86, PD-L1 and ICAM-1 positive cells. Values are the mean $\pm S D(n=3)$. One-way ANOVA was used for multiple comparisons. $\left({ }^{*} \mathrm{p}<0.05\right.$ and ${ }^{* *}$ $\mathrm{p}<0.01$ ). 
To evaluate whether CaMKIV signal interferes with the co-stimulatory signal molecules expression in muscle cells, we turned to FACS analysis for CaMKIV knocked-myoblasts or -myotubes under IFN- $\gamma$ stimulation. As expected, a higher proportion of CD40, CD86, PD-L1 or ICAM-1 positive myoblasts and myotubes were found in sc shRNA treated control cells received IFN- $\gamma$ treating, as compared to cells with no IFN- $\gamma$ treating (Fig. 5). In contrast, CaMKIV knockdown inhibited IFN- $\gamma$ induced expression of CD40, CD86 and ICAM-1 in muscle cells, because the positive cell number significantly decreased (Fig. 5). Interestingly, we found CaMKIV knockdown had little effect on the percentage of PD-L1 positive cells in the presence of IFN- $\gamma$ (Fig. 5). Since PD-L1 has been reported to exert strong immuno-inhibitory function, this result would be in agreement with the finding that endogenous CaMKIV works as a positive regulator for immune cell functions [29].

CaMKIV knockdown abolishes IFN- $\gamma$ induced CREB pathway molecules accumulation in differentiated myotubes

In immune cells (e.g., macrophage), IFN- $\gamma$-induced cellular responses are mediated mainly through Jak-Stat activation [30]. In addition, cAMP response element-binding protein

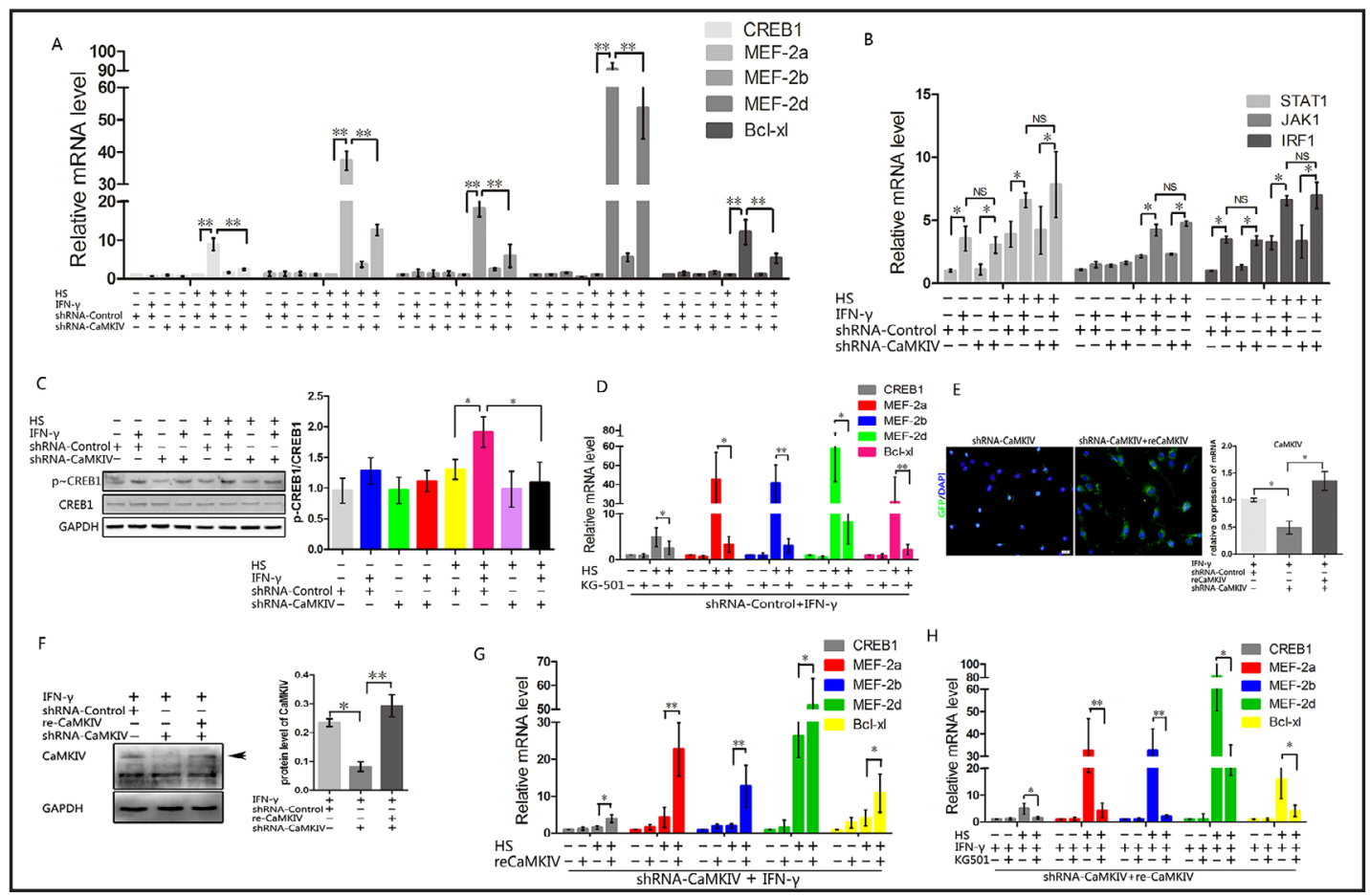

Fig. 6. CaMKIV knockdown abolishes IFN- $\gamma$ induced CREB pathway molecules accumulation in differentiated myotubes. (A) qRT-PCR detects mRNA levels of CREB pathway molecule CREB1, Bcl-xl and MEF-2 in CaMKIV knockdown cells and in sc shRNA control cells; (B) qRT-PCR detects mRNA levels of Jak-Stat pathway molecule Stat1, IRF-1 and JAK1 in CaMKIV knockdown cells and in sc shRNA control cells; (C) Western blots analyzes p-CREB1 protein level in CaMKIV knockdown cells and in sc shRNA control cells; (D) qRT-PCR detects mRNA levels of CREB1, Bcl-xl and MEF-2 in sc shRNA control cells received CREB blocker KG-501; (E) GFP fluorescence and PCR detection of re-expression of CaMKIV gene in CaMKIV knockdown cells; (F) Western blots detects re-expression of CaMKIV protein in CaMKIV knockdown cells; (G) qRT-PCR detects mRNA levels of CREB1, Bcl-xl and MEF-2 in CaMKIV re-expression cells; (H) qRT-PCR detects mRNA levels of CREB1, Bcl-xl and MEF-2 in CaMKIV re-expression cells after KG-501 treatment. Black arrow indicates CaMKIV band. The relative band intensities from western blots experiments were normalized to the level of GAPDH. One-way ANOVA was used for multiple comparisons. All data are presented as mean \pm SD $(n=3) .(*$ $\mathrm{p}<0.05$ and ${ }^{* *} \mathrm{p}<0.01 ; \mathrm{NS}$ : no significant difference). Bar $=20 \mu \mathrm{m}$.

\section{KARGER}


(CREB) is thought as the co-regulator of the IFN- $\gamma$ signaling pathway. Noteworthy, the key effects of CaMKIV in cells of the immune system involve modulation of the activity of CREB, its co-activator CBP and the myocyte enhancer factor-2 (MEF-2) [31]. In order to address IFN- $\gamma$ activated downstream signaling in muscle cells, and to further determine whether CaMKIV mediates the IFN- $\gamma$ activation signaling in muscle cells, we investigated gene levels of the key molecules of Jak-Stat and CREB signal pathways in IFN- $\gamma$-treated myoblasts and myotubes knocked down CaMKIV or not. Our qRT-PCR data verified that, in the sc shRNA transfected control $\mathrm{C}_{2} \mathrm{C}_{12}$ cells, especially in myotubes (72 h differentiation), IFN- $\gamma$ induced a significant mRNA level increase of CREB pathway molecule CREB1, Bcl-xl and MEF-2 ( $a, b$ and d), and of Jak-Stat pathway molecule Stat1, IRF-1 and JAK1 (Fig. 6A, B). In striking contrast, in CaMKIV knocked myotubes, but not myoblasts, IFN- $\gamma$ failed to induce up-regulation of gene levels of CREB1, Bcl-xl and MEF-2. Instead, Stat1, IRF-1 and JAK1 levels are not affected by CaMKIV knockdown (Fig. 6A, B). Hence, it is possible that CaMKIV mediates IFN- $\gamma$-activated CREB signal pathway in muscle cells. To definitively establish this point, we further explored CREB1 activation in CaMKIV knocked cells. As a result, we observed the significant down-regulation for p-CREB1 protein level in IFN- $\gamma$-treated myotubes after CaMKIV knockdown, as compared to that of IFN- $\gamma$-treated control cells (received sc shRNA transfection) (Fig. 6C). Since IFN- $\gamma$ and lentivirus transduction may induce numerous genes activation, and the up-regulation of CREB pathway molecules in muscle cells may not necessarily mediated by CaMKIV, we next assessed the CaMKIV effects on CREB pathway molecules in muscle cells after CREB signal blockade in vitro. In the IFN- $\gamma$-induced pro-inflammatory condition, when we added CREB1 antagonist KG-501 into the culturing system of the sc shRNA transfected control cells, we detected markedly decrease of CREB1, Bcl-xl and MEF-2 gene levels, as comparing to cells with no KG-501 treating (Fig. 6D), suggesting that IFN- $\gamma$ induced up-regulation of CREB pathway molecule levels in muscle cells is not affected by lentivirus treatment. When we performed CaMKIV recover transfection (reCaMKIV) to correct intracellular CaMKIV level of knocked cells (Fig. 6E, F), we found CREB1, Bcl-xl and MEF-2 gene level significantly increased, compared to the knocked cells (Fig. 6G). However, when we further added KG501 into this cell system, CREB1, Bcl-xl and MEF-2 gene level decreased again (Fig. 6H). It, therefore, appears that CaMKIV mediates IFN- $\gamma$-activated CREB signal pathway in muscle cells.

\section{Discussion}

CaMKIV is a multifunctional Ser/Thr kinase encoded by the CaMKIV gene, which requires $\mathrm{Ca}^{2+} / \mathrm{CaM}$ for its activity [31]. This enzyme is considered as a necessary element for function of calcium in immune, and regulates various cellular events through phosphorylation of transcription factors which play pivotal roles in immune response and inflammation [31, 32]. During skeletal muscle pathologic state (e.g., myositis), muscle cells can express a variety of immunologically important molecules, and can actively participate in local immune reactions $[33,34]$. Recently, using CTX induced mice myoinjury model, we found the regenerated myofibers up-regulate CaMKIV level in inflammatory condition, and CaMKIV can act as an immunostimulation molecule to enhance the acute muscle inflammatory responses [19]. In this work, we further show the importance of endogenous CaMKIV in impacting on the intrinsic immunological properties of muscle cells under pro-inflammatory condition.

CaMKIV is differentially expressed in adult thymocyte subsets, and affects $\mathrm{T}$ cell development. Studies in CaMKIV - - mice confirmed the enzyme signal contributes to subsets selection, survival, activation, proliferation and function of $\mathrm{T}$ cell [35]. In addition, CaMKIV is reported to prompt the viability and proliferation of monocyte-derived dendritic cells exposed to bacterial lipopolysaccharides [4]. From the previous reports, CaMKIV protein is not detectable in murine and human skeletal muscle, and therefore CaMKIV is considered to be not required for the maintenance of muscle fiber phenotype and basal level mitochondrial biogenesis [18]. In agreement, we also noticed the absence of CaMKIV gene and protein

\section{KARGER}


expression in cultured and in differentiated $\mathrm{C}_{2} \mathrm{C}_{12}$ cells and MPCs. Interestingly, we observed CaMKIV gene knockdown has no impact on survival, proliferation and fusion of $\mathrm{C}_{2} \mathrm{C}_{12}$ cells, which further evidences CaMKIV does not directly interfere with gene expression linked to muscle cell viability, adaption and function. Of note, we found CaMKIV protein expressed or up-regulated in muscle cells received pro-inflammatory IFN- $\gamma$ stimuli, suggesting endogenous CaMKIV is necessary for muscle cells responding to the special inflammatory milieu.

Recent work has shown that CaMKIV regulates terminal differentiation and survival of APCs. Genetic ablation of CaMKIV in monocyte-derived dendritic cells leads to a marked defect in typical markers of mature myeloid DC in response to LPS, involving MHC-II molecule I-A and TLR4 [15] . Skeletal muscle cells have been proposed to be the facultative APCs. Cultured human myoblasts express constitutively the classical human leukocyte (HLA) class I antigens, TLR3 and TLR7, and the expression level is increased by proinflammatory cytokines (e.g. IFN- $\gamma$, TNF- $\alpha$, IL-1 $\alpha$, et al.) $[10,12]$, which hints muscle cells can actively participate in local immune reactions. In line with this, we observed the obvious expression up-regulation of $\mathrm{H}-2 \mathrm{~K}^{\mathrm{b}}$ (MHC-I), TLR3 and H2-Ea (MHC-II) in myoblasts and myotubes in the presence of proinflammatory IFN- $\gamma$. Recently, we found the up-regulation of active CaMKIV protein in Cardiotoxin-damaged TA muscle in B6 mice [19], which raises an important question, whether CaMKIV signaling only acts on intramuscular infiltrated lymphocytes, or interferes with immunological capacities of muscle cells simultaneously? In this study, we provide evidence for a positive regulation role of CaMKIV in the immune behaviors of muscle cells. Our present data shown that, CaMKIV gene knockdown can reverse IFN- $\gamma$-induced upregulation of MHC-I/II and TLR3 in $\mathrm{C}_{2} \mathrm{C}_{12}$ myoblasts and myotubes. As well, some inducible co-stimulatory molecules, involving CD40, CD86 and ICAM-1, were significantly suppressed by CaMKIV knockdown in myoblasts and myotubes. Of note, we detected CaMKIV knockdown has no effect on PD-L1 expression in IFN- $\gamma$ induced $\mathrm{C}_{2} \mathrm{C}_{12}$ cells. Since PD-L1 exerts immunoinhibitory function [29], this finding further support CaMKIV is a positive intervention factor for muscle immune behaviors.

Muscle cells are capable of secreting soluble mediators as well as immunocompetent cells invading the muscle tissue during the inflammation stage [36]. Alternatively, human myoblasts can be induced to produce IL-6, IL-1 $\alpha$, IL-1 $\beta$ and TNF- $\alpha$ in vitro [37-39]. Consistently, we also found, in IFN- $\gamma$ constructed inflammatory milieu, myoblasts and myotubes upregulated mRNA levels of IL-1 $\beta$, IL- 6 and MIP- $1 \alpha$, and additionally, myotubes up-regulated TNF- $\alpha$ and MCP-1 levels. CaMKIV has been proposed to control the activity of cytokines in APCs, T cell and B cells. Macrophage from CaMKIV---mice reduced IL-6 production [40]. As well, CaMKIV-/- mice sourced CD4 memory T cells are markedly defect in the synthesis of IL-2, IL-4 and IFN- $\gamma$, because of their inability to phosphorylate CREB in response to TCR stimulation [41]. In B cells from MRL/lpr mice, CaMKIV antagonist KN-93 was able to block LPS-induced production of IFN- $\gamma$ and to significantly reduce the secretion of TNF- $\alpha$ [5]. Our results show that, knockdown of CaMKIV attenuates IFN- $\gamma$ induced up-regulation of IL- $1 \beta$, IL-6, TNF- $\alpha$, MIP- $1 \alpha$ and MCP-1 in myotubes. This data further support the involvement of CaMKIV signal in interfering with crucial immune phenotype of muscle cells in vitro.

IFN- $\gamma$ is a macrophage-activating cytokine that serves critical functions in innate and adaptive immunity and is thought to be mediated by the Jak-Stat signaling pathway [30]. Besides, IFN- $\gamma$ has been suggested to mediate immune cell response through regulating cAMP/ PKA/CREB signal [42]. Exposure of muscle cells to IFN- $\gamma$ can up-regulate immunological important molecules, including MHC and co-stimulatory molecules, thus induces muscle cells to be the facultative APCs $[43,44]$. We demonstrated herein that, in IFN- $\gamma$ provoked myoblasts and myotubes, both of CREB and Jak-Stat pathway molecules significant increased. Noteworthy, CaMKIV inhibition alternatively abolishes IFN- $\gamma$ induced up-regulation of CREB pathway molecules, as well, CaMKIV inhibition reverses the IFN- $\gamma$ induced CREB1 activation in myotubes. Moreover, CaMKIV recover transfection makes the re-increase of CREB1, Bcl-xl and MEF-2 level in knocked cells. In macrophages and DCs, CaMKIV functions as a physiological inducer of CREB activation in response to increased intracellular $\mathrm{Ca}^{2+}$. CaMKIV-dependent phosphorylation of CREB, and the activation of downstream molecules, 
is involved in the regulation of differentiation and survival of monocyte-derived immune cells [31]. From the present data, it is possible that CaMKIV mediates IFN- $\gamma$-activated CREB signal pathway in muscle cells.

Although $\mathrm{C}_{2} \mathrm{C}_{12}$ myoblasts and myotubes represent the most widely accepted in vitro system to investigate and characterize the biological properties of skeletal muscle cells, it should be noted that the usage of CaMKIV knocked $\mathrm{C}_{2} \mathrm{C}_{12}$ cells instead of primary MPC cells is still a limitation for determining the role of CaMKIV on regulating intrinsic immunologic features of muscle cells, and we believe the detailed mechanisms leading CaMKIV to impact immune capacities of muscle cells can be revealed through the use of the muscle conditional CaMKIV gene knockout model.

\section{Acknowledgements}

This study has been supported by grants from the National Natural Science Foundation of China (81371924) and (81572102), National Key Research and Development Plan (2017YFC1105003), and GuangDong Provincial Natural Science Foundation (2014A030313276).

All authors were involved in drafting the article or revising it critically for important intellectual content, and all authors approved the final version to be published. Dr. Hua Liao had full access to all of the data in the study and takes responsibility for the integrity of the data and the accuracy of the data analysis.

\section{Disclosure Statement}

The authors have declared that no competing interests exists.

\section{References}

1 Chow FA, Anderson KA, Noeldner PK, Means AR: The autonomous activity of calcium/calmodulindependent protein kinase IV is required for its role in transcription. J Biol Chem 2005;280:20530-20538.

2 Song N, Nakagawa S, Izumi T, Toda H, Kato A, Boku S, Inoue T, Sakagami H, Li X, Koyama T: Involvement of CaMKIV in neurogenic effect with chronic fluoxetine treatment. Int J Neuropsychopharmacol 2013;16:803812.

- I Ichinose K, Ushigusa T, Nishino A, Nakashima Y, Suzuki T, Horai Y, Koga T, Kawashiri S-y, Iwamoto N, Tamai M, Arima K, Nakamura H, Obata Y, Yamamoto K, Origuchi T, Nishino T, Kawakami A, Tsokos GC: Lupus Nephritis IgG Induction of Calcium/Calmodulin-Dependent Protein Kinase IV Expression in Podocytes and Alteration of Their Function. Arthritis Rheum 2016;68:944-952.

-4 Illario M, Giardino-Torchia ML, Sankar U, Ribar TJ, Galgani M, Vitiello L, Masci AM, Bertani FR, Ciaglia E, Astone D, Maulucci G, Cavallo A, Vitale M, Cimini V, Pastore L, Means AR, Rossi G, Racioppi L: Calmodulindependent kinase IV links Toll-like receptor 4 signaling with survival pathway of activated dendritic cells. Blood 2008;111:723-731.

5 Ichinose K, Juang Y-T, Crispin JC, Kis-Toth K, Tsokos GC: Suppression of Autoimmunity and Organ Pathology in Lupus-Prone Mice Upon Inhibition of Calcium/Calmodulin-Dependent Protein Kinase Type IV. Arthritis Rheum 2011;63:523-529.

6 Nakaya HI, Wrammert J, Lee EK, Racioppi L, Marie-Kunze S, Haining WN, Means AR, Kasturi SP, Khan N, Li G-M, McCausland M, Kanchan V, Kokko KE, Li S, Elbein R, Mehta AK, Aderem A, Subbarao K, Ahmed R, Pulendran B: Systems biology of vaccination for seasonal influenza in humans. Nat Immunol 2011;12:786U149. 


\section{Cellular Physiology Cell Physiol Biochem 2018;46:351-364

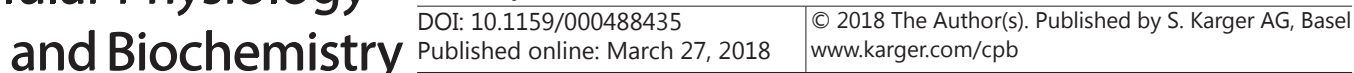

7 Iwasa K, Kato-Motozaki Y, Furukawa Y, Maruta T, Ishida C, Yoshikawa H, Yamada M: Up-regulation of MHC class I and class II in the skeletal muscles of myasthenia gravis. J Neuroimmunol 2010;225:171-174.

8 Higuchi I, Nerenberg M, Ijichi T, Fukunaga H, Arimura K, Usuki F, Kuriyama M, Osame M: Vacuolar myositis with expression of both MHC class I and class II antigens on skeletal muscle fibers. J Neurol Sci 1991;106:60-66.

-9 Englund P, Lindroos E, Nennesmo I, Klareskog L, Lundberg IE: Skeletal muscle fibers express major histocompatibility complex class II antigens independently of inflammatory infiltrates in inflammatory myopathies. Am J Pathol 2001;159:1263-1273.

10 Garlepp MJ, Chen W, Tabarias H, Baines M, Brooks A, McCluskey J: Antigen processing and presentation by a murine myoblast cell line. Clin Exp Immunol 1995;102:614-619.

-11 Bao S, dos Remedios CG, King NJ: Ontogeny of major histocompatibility complex antigen expression on cultured human embryonic skeletal myoblasts. Transplantation 1994;58:585-591.

12 Tournadre A, Lenief V, Miossec P: Expression of Toll-like Receptor 3 and Toll-like Receptor 7 in Muscle Is Characteristic of Inflammatory Myopathy and Is Differentially Regulated by Th1 and Th17 Cytokines. Arthritis Rheum 2010;62:2144-2151.

13 Wiendl H, Hohlfeld R, Kieseier BC: Immunobiology of muscle: advances in understanding an immunological microenvironment. Trends Immunol 2005;26:373-380.

14 Goh Q Dearth CL, Corbett JT, Pierre P, Chadee DN, Pizza FX: Intercellular adhesion molecule-1 expression by skeletal muscle cells augments myogenesis. Exp Cell Res 2015;331:292-308.

15 Jensen EB, Zheng D, Russell RA, Bassel-Duby R, Williams RS, Olson AL, Dohm GL: Regulation of GLUT4 expression in denervated skeletal muscle. Am J Physiol Regul Integr Comp Physiol 2009;296:R1820-R1828.

16 Guerfali I, Manissolle C, Durieux A-C, Bonnefoy R, Bartegi A, Freyssenet D: Calcineurin A and CaMKIV transactivate PGC-1 alpha promoter, but differentially regulate cytochrome c promoter in rat skeletal muscle. Pflugers Arch 2007;454:297-305.

17 Wu H, Kanatous SB, Thurmond FA, Gallardo T, Isotani E, Bassel-Duby R, Williams RS: Regulation of mitochondrial biogenesis in skeletal muscle by CaMK. Science (New York, N.Y.) 2002;296:349-352.

18 Akimoto T, Ribar TJ, Williams RS, Yan Z: Skeletal muscle adaptation in response to voluntary running in $\mathrm{Ca} 2+/$ calmodulin-dependent protein kinase IV-deficient mice. Am J Physiol Cell Physiol 2004;287:C1311-C1319.

19 Shi D, Gu R, Song Y, Ding M, Huang T, Guo M, Xiao J, Huang W, Liao H: Calcium/Calmodulin-Dependent Protein Kinase IV (CaMKIV) Mediates Acute Skeletal Muscle Inflammatory Response. Inflammation 2018;41:199-212.

20 Sciorati C, Monno A, Ascherman DP, Seletti E, Manfredi AA, Rovere-Querini P: Required Role of Apoptotic Myogenic Precursors and Toll-like Receptor Stimulation for the Establishment of Autoimmune Myositis in Experimental Murine Models. Arthritis Rheum 2015;67:809-822.

-21 Best JL, Amezcua CA, Mayr B, Flechner L, Murawsky CM, Emerson B, Zor T, Gardner KH, Montminy M: Identification of small-molecule antagonists that inhibit an activator: coactivator interaction. Proc Natl Acad Sci U S A 2004;101:17622-17627.

-22 Nozaki K, Das A, Ray SK, Banik NL: Calpain inhibition attenuates intracellular changes in muscle cells in response to extracellular inflammatory stimulation. Exp Neurol 2010;225:430-435.

23 Yuan JS, Reed A, Chen F, Stewart CN: Statistical analysis of real-time PCR data. BMC Bioinformatics 2006; 7:

24 Lundberg I, Ulfgren AK, Nyberg P, Andersson U, Klareskog L: Cytokine production in muscle tissue of patients with idiopathic inflammatory myopathies. Arthritis Rheum 1997;40:865-874.

25 De Bleecker JL, De Paepe B, Vanwalleghem IE, Schroder JM: Differential expression of chemokines in inflammatory myopathies. Neurology 2002;58:1779-1785.

-26 Prelovsek 0, Mars T, Jevsek M, Podbregar M, Grubic Z: High dexamethasone concentration prevents stimulatory effects of TNF-alpha and LPS on IL-6 secretion from the precursors of human muscle regeneration. Am J Physiol Regul Integr Comp Physiol 2006;291:R1651-R1656.

27 Sugiura T, Kawaguchi Y, Harigai M, Takagi K, Ohta S, Fukasawa C, Hara M, Kamatani N: Increased CD40 expression on muscle cells of polymyositis and dermatomyositis: role of CD40-CD40 ligand interaction in IL-6, IL-8, IL-15, and monocyte chemoattractant protein-1 production. J Immunol (Baltimore, Md. : 1950) 2000;164:6593-6600.

-28 Dalakas MC: Inflammatory disorders of muscle: progress in polymyositis, dermatomyositis and inclusion body myositis. Curr Opin Neurol 2004;17:561-567. 


\section{Cellular Physiology Cell Physiol Biochem 2018;46:351-364

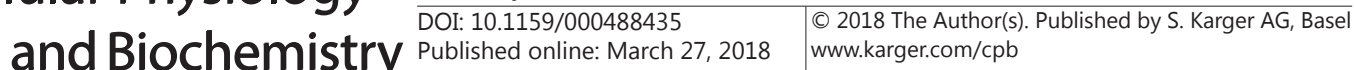

Gu et al.: CaMKIV Impacts on Immune Behaviors of Muscle Cells

29 Hewitt RE, Pele LC, Tremelling M, Metz A, Parkes M, Powell JJ: Immuno-inhibitory PD-L1 can be induced by a Peptidoglycan/NOD2 mediated pathway in primary monocytic cells and is deficient in Crohn's patients with homozygous NOD2 mutations. Clin Immunol 2012;143:162-169.

-30 Zhou F: Molecular Mechanisms of IFN-gamma to Up-Regulate MHC Class I Antigen Processing and Presentation. Int Rev Immunol 2009;28:239-260.

-31 Racioppi L, Means AR: Calcium/calmodulin-dependent kinase IV in immune and inflammatory responses: novel routes for an ancient traveller. Trends Immunol 2008;29:600-607.

-32 Colomer J, Means AR: Physiological roles of the Ca2+/CaM-dependent protein kinase cascade in health and disease. Subcell Biochem 2007;45:169-214.

33 Venalis P, Lundberg IE: Immune mechanisms in polymyositis and dermatomyositis and potential targets for therapy. Rheumatology 2014;53:397-405.

34 Stuebgen J-P: A review on the association between inflammatory myopathies and vaccination. Autoimmun Rev 2014;13:31-39.

-35 Pan F, Means AR, Liu J: Calmodulin-dependent protein kinase IV regulates nuclear export of Cabin1 during T-cell activation. EMBO J 2005;24:2104-2113.

-36 Smith C, Kruger MJ, Smith RM, Myburgh KH: The Inflammatory Response to Skeletal Muscle Injury Illuminating Complexities. Sports Med 2008;38:947-969.

37 Bartoccioni E, Michaelis D, Hohlfeld R: Constitutive and cytokine-induced production of interleukin- 6 by human myoblasts. Immunol Lett 1994;42:135-138.

-38 Marino M, Scuderi F, Mazzarelli P, Mannella F, Provenzano C, Bartoccioni E: Constitutive and cytokineinduced expression of MHC and intercellular adhesion molecule-1 (ICAM-1) on human myoblasts. J Neuroimmunol 2001;116:94-101.

-39 De Rossi M, Bernasconi P, Baggi F, de Waal Malefyt R, Mantegazza R: Cytokines and chemokines are both expressed by human myoblasts: possible relevance for the immune pathogenesis of muscle inflammation. Int Immunol 2000;12:1329-1335.

40 Zhang X, Howell GM, Guo L, Collage RD, Loughran PA, Zuckerbraun BS, Rosengart MR: CaMKIV-Dependent Preservation of mTOR Expression Is Required for Autophagy during Lipopolysaccharide-Induced Inflammation and Acute Kidney Injury. J Immunol 2014;193:2405-2415.

41 Anderson KA, Means AR: Defective signaling in a subpopulation of CD4(+) T cells in the absence of $\mathrm{Ca}(2+) /$ calmodulin-dependent protein kinase IV. Mol Cell Biol 2002;22:23-29.

42 Liu L, Wang Y, Fan Y, Li CL, Chang ZL: IFN-gamma activates cAMP/PKA/CREB signaling pathway in murine peritoneal macrophages. J Interferon Cytokine Res 2004;24:334-342.

43 Cao B, Bruder J, Kovesdi I, Huard J: Muscle stem cells can act as antigen-presenting cells: implication for gene therapy. Gene Ther 2004;11:1321-1330.

44 Marino M, Scuderi F, Provenzano C, Bartoccioni E: Skeletal muscle cells: from local inflammatory response to active immunity. Gene Ther 2011;18:109-116. 